\title{
A FORMAÇÃO CONTINUADA EM ATENDIMENTO EDUCACIONAL ESPECIALIZADO: UMA EXPERIÊNCIA NO AMBIENTE VIRTUAL DE APRENDIZAGEM EUREKA
}

\author{
LA FORMACIÓN CONTINUA EN ESPECIALISTA DE SERVICIO EDUCATIVO: \\ UNA EXPERIENCIA EN AMBIENTE VIRTUALES DE APRENDIZAJE EUREKA
}

A CONTINUING EDUCATION SPECIALIZED TRAINING SERVICE: AN
EXPERIENCE IN VIRTUAL LEARNING ENVIRONMENT EUREKA

Paulo Vinicius Tosin da SILVA ${ }^{1}$

Gislaine Coimbra BUDEL ${ }^{2}$

Paulo Ricardo ROSS ${ }^{3}$

RESUMO: Símbolo da contemporaneidade, a Educação a Distância desponta como tendência no cenário educacional do século XXI, haja vista o grande número de pessoas conectadas no mundo inteiro, reflexo do processo de globalização e volatilidade da informação. Em contrapartida, exige maior comprometimento do aluno que se lança nesta proposta de aprendizagem. A educação em sua concepção ampla é um processo contínuo que visa o aperfeiçoamento do ser em suas faculdades mentais até níveis mais elevados, e a busca de saberes que respondam às demandas sociais. Sem distinção de méritos na educação, a formação continuada impõe-se como cerne da postura docente na atualidade, haja vista a sociedade em constante transformação, que é por sua vez acelerada pelas tecnologias da informação. Sendo assim, o presente artigo retrata a experiência de um curso sobre Atendimento Educacional Especializado em Salas de Recursos Multifuncionais ofertado na Plataforma Eureka da Pontifícia Universidade Católica do Paraná, relatando as expectativas dos cursistas em relação ao Atendimento Educacional Especializado em Salas de Recursos Multifuncionais, as dificuldades na promoção da inclusão de alunos com necessidades especiais, além do próprio desenho didático do curso no que se refere à sua aplicabilidade. Os resultados apontam para necessidade de formação continuada em educação inclusiva com ênfase para o Atendimento Educacional Especializado, que seja de caráter prático, isto é, seu embasamento esteja concatenado com a realidade do aluno com necessidades especiais.

PALAVRAS-CHAVE: Formação continuada. Atendimento educacional Especializado. educação a distância.

\footnotetext{
${ }^{1}$ Universidade Federal do Paraná (UFPR), Curitiba - PR - Brasil. Professor de Geografia na Secretaria de Estado da Educação do Paraná - SEED/PR. E-mail: pauloviniciustosin@ gmail.com

${ }^{2}$ Pontifícia Universidade Católica do Paraná (PUCPR), Curitiba - PR - Brasil. Professora de cursos de pósgraduação e graduação da Pontifícia Universidade Católica do Paraná e Faculdade Doutor Leocádio José Correia. Atualmente é Diretora do Departamento de Inclusão e Atendimento Educacional Especializado, da Secretaria Municipal da Educação de Curitiba. E-mail: gislaine.pedago@hotmail.com

${ }^{3}$ Universidade Federal do Paraná (UFPR), Curitiba - PR - Brasil. Professor Titular do Departamento de Planejamento da Educação da Universidade Federal do Paraná (UFPR). Doutor em Educação Especial pela Universidade de São Paulo (USP). E-mail: profpauloross@gmail.com
} 
RESUMEN: Símbolo contemporáneo, la educación a distancia, aparece como una tendencia en el panorama educativo del siglo XXI, dado el gran número de personas conectadas en todo el mundo, lo que refleja el proceso de globalización y la volatilidad de la información. Por otra parte se requiere una mayor participación de los estudiantes que se pone en marcha este aprendizaje propuesta. La educación en el sentido más amplio, es un proceso continuo dirigido a la mejora de estar en sus facultades mentales a niveles más altos y la búsqueda del conocimiento que responden a las demandas sociales. Sin distinción de mérito en la educación, la formación continua se impone como el núcleo de la posición de enseñanza en la actualidad, dada la sociedad en transformación constante que es por su tiempo acelerado por la tecnología de la información. Por lo tanto, este artículo describe la experiencia de un curso de Servicio Educativo Especializado en Recursos Multifunción habitaciones que se ofrecen en la Plataforma de Eureka la Pontificia Universidad Católica de Paraná, reportando las expectativas de los participantes del curso en relación con el Servicio Educativo Especializado en salas de recursos de múltiples funciones, el dificultades en la promoción de la inclusión de los alumnos con necesidades especiales, además de nuestro propio diseño de los cursos de enseñanza con respecto a su aplicabilidad. Los resultados apuntan a la necesidad de la formación continua en la educación inclusiva con énfasis en el servicio de enseñanza de régimen especial que es de carácter práctico, es decir, su fundación se concatena con la realidad de los estudiantes con necesidades especiales.

PALABRAS CLAVE: Educación continua. Especialista de servicio educativo. Educación a distancia.

ABSTRACT: A symbol of contemporaneity, Distance Education, emerges as a trend in the educational scene of the 21st century, given the large number of people connected throughout the world, reflecting the process of globalization and information volatility. On the other hand, it requires a greater commitment from the student who embarks on this learning proposal. Education in its broad conception is a continuous process that seeks to perfect the being in its mental faculties to higher levels and the search for knowledge that respond to social demands. Without distinction of merit in education, continuing education is at the core of today's teaching position, given the ever-changing society, which is in turn accelerated by information technologies. Thus, the present article portrays the experience of a course on Specialized Educational Attendance in Multifunctional Resource Rooms offered at the Eureka Platform of the Pontifical Catholic University of Paraná, reporting the expectations of the students in relation to the Specialized Educational Attendance in Multifunctional Resource Rooms, the Difficulties in promoting the inclusion of students with special needs, in addition to the course design itself with regard to its applicability. The results point to the need for continuing education in inclusive education, with emphasis on the Specialized Educational Assistance that is practical in nature, that is, its foundation is linked to the reality of the student with special needs.

KEYWORDS: Continuing education. Specialized educational assistance. Distance education. 


\section{Introdução}

A inclusão de alunos com necessidades educacionais especiais é a tônica do discurso educacional, principalmente após a Declaração de Salamanca em 1994. A sociedade civil, formada por professores e seus respectivos sistemas de ensino administrados pelos governos municipal, estadual ou federal, assim como as entidades filantrópicas e organizações não-governamentais, se propuseram a pensar e propor ações que efetivassem o acesso e permanência dos alunos de inclusão.

Paralelamente, a demanda por profissionais capacitados para oferecer um ensino inclusivo de fato apresentou-se não como alternativa, ao invés, como demanda de uma sociedade que excluiu seus "anormais" durante o transcorrido de sua história.

Salvaguardadas suas exceções, os cursos de formação inicial de professores, a exemplo das licenciaturas e cursos técnicos de nível médio, são deficitários ${ }^{4}$ em razão de seus currículos serem extensos e conteudistas; não se trata de currículo mínimo, mas de recortes a serem realizados pelos respectivos cursos.

Deste modo, os cursos de formação continuada se apresentam como oportunidade de uma nova aprendizagem, complementação ou atualização profissional.

Remontando às últimas décadas do século passado, temos o despontamento da Educação a Distância (EaD) como tendência de modalidade de ensino. Esse fenômeno tecnológico e educacional tem como cerne de seu desenvolvimento a chamada Era da Informação.

Diante deste retrospecto apresentado, a presente publicação realiza uma análise do discurso a partir de um curso de formação continuada com ênfase no Atendimento Educacional Especializado em Salas de Recursos Multifuncionais que, além de oferecer formação continuada sobre o tema, buscou analisar a necessidade deste conhecimento pelos cursistas.

Sobre este artigo, o mesmo encontra-se estruturado em três seções: a primeira, denominada "A formação continuada em Atendimento Educacional Especializado em Salas de Recursos Multifuncionais", contempla os aspectos da formação docente na educação inclusiva, em seu braço do Atendimento Educacional Especializado, bem como o conceito e estruturação das Salas de Recursos Multifuncionais; a segunda seção faz um

\footnotetext{
${ }^{4}$ Deficitários no sentido da ausência de disciplinas e conteúdos que tratem de metodologias, estratégias e recursos adequados ao ensino de alunos com necessidades educacionais especiais, excetuando-se cursos específicos de Graduação/Formação de Professores em Educação Especial.
} 
breve retrospecto da Educação a Distância, sua importância no presente contexto social e as performances que os cursos devem assumir para que se tornem abrangentes e aplicáveis.

Como escopo desta produção cientifica, a terceira seção reporta-se às análises dos questionários respondidos pelos alunos participantes do curso anteriormente citado. Tratando-se de uma pesquisa qualitativa, a metodologia é o Estudo de Caso com base na análise do discurso. Trata-se de Estudo de Caso (FLICK, 2004; GIL, 2008; MALHEIROS, 2011), caracterizado "pelo estudo profundo e exaustivo de um ou de poucos objetos, de maneira a permitir conhecimento amplo e detalhado do mesmo". (GIL, 2008)

\title{
A formação continuada em Atendimento Educacional Especializado em Salas de Recursos Multifuncionais
}

De acordo com a Nota Técnica - SEESP/GAB/N 11/2010 (Brasil, 2010), que dispõe sobre a oferta do Atendimento Educacional Especializado e implantação de Salas de Recursos Multifuncionais, a institucionalização destas compete aos sistemas de ensino nas escolas localizadas em áreas urbanas, rurais, indígenas ou quilombolas, sendo presencial ou semipresencial. Ademais, o Atendimento Educacional Especializado (AEE) em Salas de Recursos Multifuncionais (SRMF) visa à complementação da aprendizagem do aluno com necessidades especiais. Em hipótese alguma visa à substituição do ensino regular, portanto o AEE em SRMF deve ser ofertado no período do contraturno escolar.

Segundo a SEESP/MEC, o Atendimento Educacional Especializado é definido como:

\begin{abstract}
$\mathrm{O}$ atendimento educacional especializado tem como função identificar, elaborar e organizar recursos pedagógicos e de acessibilidade que eliminem as barreiras para a plena participação dos alunos, considerando suas necessidades específicas. As atividades desenvolvidas no atendimento educacional especializado diferenciam-se daquelas realizadas na sala de aula comum, não sendo substitutivas à escolarização. Esse atendimento complementa e/ou suplementa a formação dos alunos com vistas à autonomia e independência na escola e fora dela. (BRASIL, 2008)
\end{abstract}

Baptista (2011), ao realizar um estudo aprofundado, em caráter estado da arte, recupera o histórico de constituição do AEE em SRMF, admitindo esta como dispositivo previsto na Educação Especial pouco utilizado até a primeira década deste século. Apoiado em Mazotta (1982), Baptista adverte que a SRMF constitui uma "ação complexa, 
articulada de múltiplas referências" (BAPTISTA, 2011, p. 66), cabendo ao professor uma função dupla de proporcionar o AEE diretamente ao aluno e indiretamente aos professores da sala comum de modo colaborativo.

Sobre as atribuições do professor do Atendimento Educacional Especializado, ainda em conformidade com a SEESP/MEC Brasil (2008), estão englobadas: a elaboração, execução e avaliação do Plano do AEE de cada aluno, direcionando a este uma estratégia de ensino diferenciada que parta das suas necessidades educacionais pertinentes somente a ele, bem como a identificação de suas habilidades adquiridas. Além destas, compete ao professor de AEE a definição de estratégias de ensino, as escolhas das abordagens e a utilização dos recursos pedagógicos adequados. Não obstante da viabilização do AEE em SRMF, cabe ao professor a elaboração de materiais didáticos e pedagógicos segundo as necessidades educacionais dos alunos atendidos, além de estar em articulação constante com os professores da sala de aula comum, com objetivo de acompanhar a aprendizagem deste aluno no ensino regular, proporcionando a participação nas atividades escolares.

Cabe lembrar que a SRMF destina-se ao trabalho das questões além de estritamente pedagógicas escolares. Em seus Planos de AEE, uma vez concatenados com o currículo, devem ser contemplados conhecimentos que permitam ao aluno com deficiência uma vida autônoma, independente e de participação social.

Ferreira (2006) conceitua e desmitifica a problemática da formação continuada. Segundo ele existe um equívoco epistemológico que se manifesta sob três vieses. O primeiro deles concebe a formação continuada enquanto necessidade, ou seja, os professores não receberam a formação inicial adequada e, portanto, precisam de complementação educacional à prática pedagógica. À luz do segundo viés, a formação continuada é enxergada como valoração das práticas pedagógicas, deste modo, as experiências, conhecimentos e competências adquiridas pelos professores em sala de aula são consideradas irrelevantes para sua formação, logo, não possuem valoração, precisando da formação continuada de caráter acadêmico científico para validação do seu respectivo repertório pedagógico. Finalmente, sob a terceira óptica, a formação continuada desempenha um papel no sentido de atualização docente, uma vez as demandas educacionais contemporâneas estarem desalinhadas com a formação inicial recebida.

Acerca dos equívocos da chamada formação continuada, Skliar (2006, p. 31) é categórico ao afirmar que: 
[...] afirma-se que a escola e os professores não estão preparados para receber os "estranhos", "os anormais", nas aulas. Não é verdade. Pareceme que ainda não existe um consenso sobre o que signifique "estar preparado" e, e muito menos, acerca de como deveria se pensar a formação quanto às políticas de inclusão propostas em todo o mundo.

A partir destas ideias, Ferreira (2006, p. 229) abandona a ideia de formação continuada e adota "desenvolvimento e aperfeiçoamento de práticas docentes". Para o autor, assumir que o docente precisa de formação continuada denota uma recusa/negação de desenvolvimento profissional baseado nas práticas cotidianas.

\section{Uma reflexão sobre o contexto da Educação a Distância}

Compreendida em sua plenitude como o retrato fidedigno da contemporaneidade, a Educação a Distância $(\mathrm{EaD})$ resulta de um processo de aprendizagem não presencial, podendo ser síncrono ou assíncrono, viabilizado através de meios tecnológicos tais como computadores, tablets, smartphones entre outros. Moran (2002) define Educação a Distância como "o processo de ensino-aprendizagem, mediado por tecnologias, onde professores e alunos estão separados espacial e/ou temporalmente".

No entanto, a proposta de $\mathrm{EaD}$ não se resume a um simples repositório de conteúdo em um Ambiente Virtual de Aprendizagem (AVA) na internet. A interface de conteúdos deve ser mais interativa e possuir um desenho didático que aproxime o aluno do AVA, fazendo com que aquele se torne partícipe do processo de ensino e aprendizagem, interaja com os demais participantes, estimule debates, proponha questionamentos, enfim, enriqueça o seu próprio e o aprendizado de seus pares por meio da aprendizagem colaborativa e participativa.

Sobre os elementos de um curso online com qualidade, Palloff e Pratt (2004, p. 142) elencam suas características e performance satisfatória de aprendizagem conforme a Figura 1. Sobre um desenho didático eficaz do curso, os autores ressaltam a questão da conexão com o currículo, o enfoque no aluno, a acessibilidade do curso, relevância de conteúdos, a aprendizagem colaborativa, interatividade, o tamanho do grupo, coesão e abordagem. 
Figura 1: Elementos de um curso ou programa online de alta qualidade

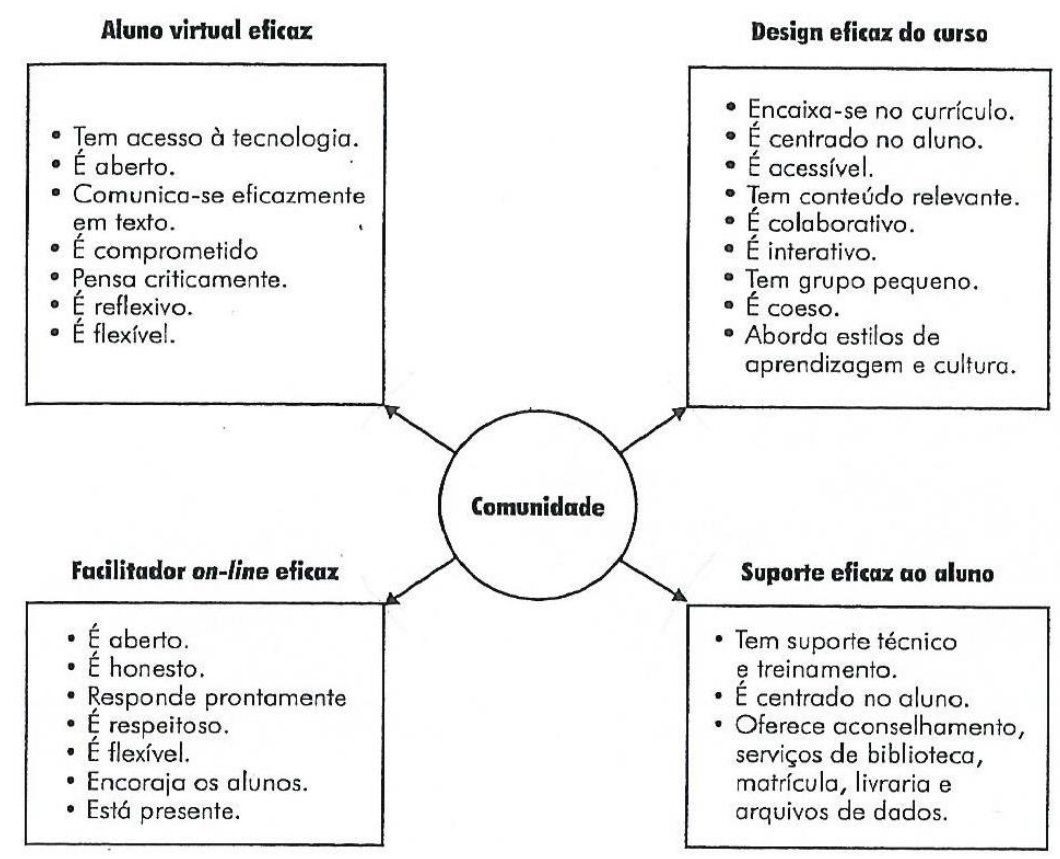

Fonte: Palloff e Pratt (2004, p. 145).

Embora o EaD tenha se difundido em todas as faixas etárias, o aluno virtual ou aluno online típico é concebido por Gilbert (2001 apud Palloff, 2004), afirmando que:

[...] há um debate constante no mundo acadêmico sobre quem é levado a estudar on-line. Tem-se como fato dado que os alunos que estudam online são adultos, pois essa espécie de aprendizagem, que se dá em qualquer lugar e a qualquer hora, permite-lhes continuar trabalhando em turno integral sem deixar de também dar atenção à família. "O aluno online 'típico' é geralmente descrito como alguém que tem mais de 25 anos, está empregado, preocupado com o bem-estar da comunidade, com alguma educação superior em andamento, podendo ser tanto do sexo masculino quanto do feminino. GILBERT (2001, p. 74 apud PALLOFF, 2004, p. 23)

Em consonância com a Associação Brasileira de Educação a Distância (ABED), segundo o Censo Ead 2014 (ABED, 2014), os cursos de formação continuada na tipologia extensão totalizavam 112.147 e 8.929 em cursos não corporativos e corporativos, respectivamente, com destaque para o ramo educacional, que concentrou 601.978 matrículas em cursos livres, o que demonstra uma crescente busca por formação e aperfeiçoamento docente. 


\section{Sobre a proposta do Curso de Atendimento Educacional Especializado em Salas de Recursos Multifuncionais}

Esta proposta de curso foi desenvolvida no âmbito da Pontifícia Universidade Católica do Paraná, dentro do Ambiente Virtual de Aprendizagem (AVA) Eureka. Foram convidados a participar alunos matriculados na disciplina de Mediação Pedagógica e Tutoria Online do Programa de Pós-graduação em Educação da PUCPR e alunos da Especialização em Educação Especial com Ênfase em Inclusão desta mesma Universidade, atingindo um total de 50 alunos.

Como descrição discursiva conceitual/procedimental (ementa) o curso teve: "O Atendimento Educacional Especializado nas Salas de Recursos Multifuncionais como complemento e suplemento à escolarização do estudante em processo de inclusão no ensino comum".

O processo de avaliação da proposta do Curso intitulado "Atendimento Educacional Especializado em Salas de Recursos Multifuncionais" ocorreu em três momentos, na forma de questionários online enviados aos que manifestaram interesse em participar deste curso.

O primeiro questionário, denominado "Avaliação Diagnóstica”, respondido por quinze participantes, tratou de coletar informações básicas sobre os participantes, tais como: idade, formação acadêmica, tempo de atuação docente e os temas julgados relevantes a serem contemplados em um curso de tal envergadura; o segundo questionário, intitulado "Avaliação Processual", respondido por sete cursistas, objetivou verificar o processo de desenvolvimento do curso nos seguintes quesitos: temas inerentes ao AEE em Salas de Recursos Multifuncionais, aplicabilidade dos conteúdos ao cotidiano docente destes profissionais e a opinião sobre o próprio desenho didático do curso.

Finalmente, o terceiro questionário abordou os aspectos formativos do curso; designado "Avaliação Formativa", respondido por cinco participantes, teve por objetivo verificar o entendimento dos participantes acerca da articulação do currículo do AEE, das dificuldades na promoção da inclusão escolar dos alunos com necessidades educacionais especiais e uma avaliação contemplativa no âmbito conteudista face à metodologia proposta pelos autores do Curso de AEE em Salas de Recursos Multifuncionais.

\section{Os resultados e as análises dos discursos dos participantes: elementos para discussão}


Participaram deste Curso de Atendimento Educacional Especializado 15 alunos, majoritariamente com idades entre 20-30 anos, reforçando a fala de Palloff e Pratt (2004) e os dados do Censo $\mathrm{EaD}$ (ABED, 2014), que revelam a tendência dos mais jovens na busca do EaD, dado este confirmado pelo Gráfico 1.

Gráfico 1: Número de participantes do Curso de AEE em SRMF

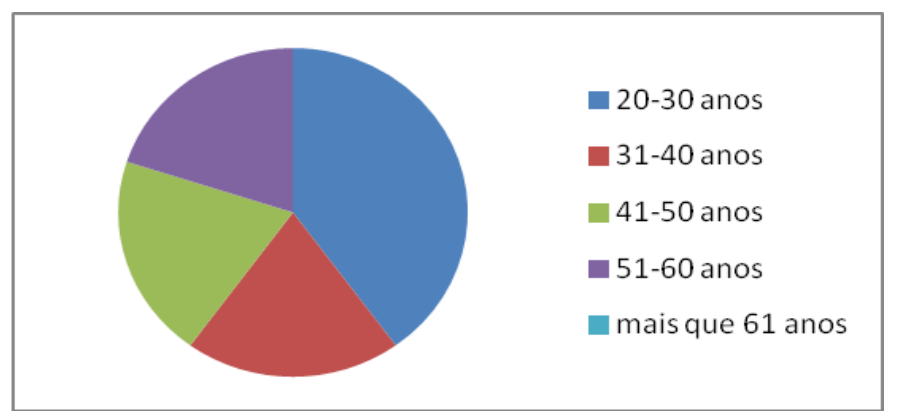

Fonte: Elaboração própria com base na Avaliação Diagnóstica, 2016.

Do universo de participantes, apenas dois não possuíam graduação em áreas ligadas à educação. Cinco participantes atuavam na rede pública de ensino, quatro na rede privada e dois em ambas as redes. Cabe ressaltar que alguns participantes foram desistindo do curso, seja por questões pessoais ou porque não sentiram-se abarcados pela proposta de aprendizagem e-learning. De tal modo, responder ou não os questionários não consistiam impeditivo para participação no curso, sendo assim, alguns participantes optaram por não responder.

Caso fossem regentes de turma, quando indagados se possuíam alunos em processos de inclusão, um participante respondeu que apresentava alunos em processo de inclusão. Embora em função análoga à regência de turma, três participantes afirmaram que acompanham o processo de inclusão de alunos com necessidades especiais dentro de suas respectivas instituições educacionais.

Sobre temas relevantes acerca da proposta de curso os participantes julgaram importantes, conforme o Quadro 1: 
Quadro 1: Temas relevantes em Atendimento Educacional Especializado segundo os participantes

\begin{tabular}{|c|c|}
\hline \multicolumn{2}{|r|}{$\begin{array}{l}\text { Considerando a proposta do curso sobre Atendimento Educacional Especializado em Salas } \\
\text { de Recurs os Multifuncionais, o que você gostaria que ele tratas se? Sobre quais as suntos referentes } \\
\text { a este tema você quer saber mais? }\end{array}$} \\
\hline P1 & "Como lidar com os alunos." \\
\hline $\mathrm{P} 2$ & $\begin{array}{c}\text { "Quem procurar (órgào, secretaria, afins) para incluir um aluno com necessidades } \\
\text { especiais da maneira adequada." }\end{array}$ \\
\hline P3 & $\begin{array}{l}\text { "Tenho interesse em saber como funciona, quais crianças podem e devem } \\
\text { frequentar, qual o tempo de atendimento por semana, quais as atividades } \\
\text { desenvolvidas, como se dá o processo de formação continuada do professor de } \\
\text { AEE em Sala de Recursos Multifuncionais." }\end{array}$ \\
\hline P4 & $\begin{array}{l}\text { "Gostaria que ele tratasse: política da inclusão, aperfeiçoamento dos professores, } \\
\text { maior número de salas multifuncionais. Estas salas são realmente efetivas?" }\end{array}$ \\
\hline P5 & P5 absteve-5e da resposta \\
\hline P6 & $\begin{array}{c}\text { "Gostaria de saber mais sobre os recursos de trabalho destas salas, suas dinâmicas } \\
\text { e seus resultados efetivos junto aos estudantes de inclusão." }\end{array}$ \\
\hline P7 & $\begin{array}{c}\text { "Uma vez que não tive oportunidade durante a graduação de entender mais o que é a } \\
\text { AEE, gostaria de aprender muito a respeito da AEE e das salas de recurso, e } \\
\text { também aprender e saber como agir da melhor maneira possivel para trabalhar com } \\
\text { uma criança que precise da sala de recursos." }\end{array}$ \\
\hline P8 & $\begin{array}{c}\text { "Gostaria de saber mais sobre tecnologia as sistiva e sua utilização, e orientações } \\
\text { gerais relacionadas a flexibilização curricular." }\end{array}$ \\
\hline P9 & "Sobre hiperatividade" \\
\hline P10 & $\begin{array}{l}\text { "Atividades adaptadas para as diversas dificuldades encontradas nestes estudantes. } \\
\text { Seus objetivos, onde deve acontecer o } \mathrm{AEE} \text {, se ele substitui o ensino regular, como } \\
\text { acontece na prática." }\end{array}$ \\
\hline P11 & "criança autista e ou/ com altas habilidades" \\
\hline P12 & "Objetivos; equipamentos; formas de atuação; necessidades, entre outros." \\
\hline P13 & $\begin{array}{c}\text { "Que abordas se algum aspecto sobre o atendimento para a inclusão de alunos } \\
\text { adultos." }\end{array}$ \\
\hline
\end{tabular}

Fonte: Elaboração própria com base na Avaliação Diagnóstica, 2016.

Conforme observado nas respostas anteriores, dispostas nas afirmações de P1, P3, P6, P10 e P12, as expectativas acerca de um curso de AEE focado em Salas de Recursos Multifuncionais permeiam o plano da promoção da inclusão, a saber, as metodologias adequadas para cada tipo de necessidade especial, os materiais pedagógicos e atividades adaptadas. 
A partir do discurso de P12 é possível inferir uma necessidade dos professores conhecerem a legislação e os órgãos capacitados a fim de promover a inclusão destes alunos com deficiência. O fato de começar sua locução com "Quem procurar" denota uma angústia e uma frustração profissional que se traduz na sensação de incapacidade frente às adversidades educacionais encontradas.

No que se refere à Avaliação Processual, os participantes responderam quais conteúdos classificariam como imprescindíveis para ampliação dos conhecimentos sobre o Atendimento Educacional Especializado. Neste caso, havia possibilidade de marcar mais de uma alternativa, conforme observável no Quadro 2:

Quadro 2: Temas relevantes em Atendimento Educacional Especializado segundo os participantes

\begin{tabular}{|l|l|}
\hline 1. Política Nacional de Educação Especial na Perspectiva da Educação Inclusiva & 5 \\
\hline 2. Nota Técnica 11/2010 - MEC & 3 \\
\hline 3. Manual de Orientação: Programa de Implantação de Salas de Recursos Multifuncionais & 4 \\
\hline 4. Aspectos legais do Atendimento Educacional Especializado & 2 \\
\hline 5. Prática do Atendimento Educacional Especializado & 4 \\
\hline
\end{tabular}

Fonte: Elaboração própria com base na Avaliação Diagnóstica, 2016.

Quando organizados em categorias os itens segundo suas envergaduras, têm-se: a) Legislação sobre inclusão, nos itens 1, 2 e 3 e b) Prática pedagógica em inclusão, nos itens 3 e 5. Novamente observa-se a opção pela prática pedagógica face à legislação sobre a temática. Segundo um participante "Conhecer a política, nota técnica e legislação é extremamente relevante, o embasamento para o fazer. Entretanto 'como fazer' é tão ou mais importante que somente conhecer a legislação pertinente." Este fragmento do discurso ressalta a ineficiência pedagógica na promoção da inclusão advinda da legislação vigente, demonstrando que as ações pedagógicas voltadas para alunos de inclusão ocorrem localizadas e por vezes restritas às paredes de concreto das salas de aula. Logo, os aspectos legais, por mais importantes que sejam, ficam em segundo plano quando o processo de inclusão clama por um savor faire.

Sobre saber-fazer, Jesus (2007, p. 75) admite que:

Não se trata aqui de negar a complexidade de atuar com grupos de alunos que nos colocam o desafio de ensinar na diversidade, nem de banalizar as especificidades que acompanham algumas condições de deficiência. $\mathrm{O}$ 
desafio que se apresenta é tentar instituir outras práticas de potencialização dos saberes-fazeres, de modo que a presença de alunos, em situação de desvantagem, de qualquer natureza, não seja paralisadora de ações docentes.

Acerca da proficuidade de se realizar um curso de AEE integralmente a distância, os participantes relataram os pontos positivos e negativos, relacionados no Quadro 3. Para esta questão, foram elencadas quatro alternativas: $1^{\text {a }}$ ) Leitura crítica e reflexiva dos materiais; $2^{a}$ ) As trocas realizadas com os colegas; $3^{\mathrm{a}}$ ) Os vídeos apresentados e $4^{\mathrm{a}}$ ) As três situações anteriores.

Quadro 3: Pontos positivos e negativos em detrimento do percurso didático do curso

\begin{tabular}{|c|c|}
\hline P1 & $\begin{array}{c}\text { "As situações devem ser integradas, pois uma depende da outra para que possamos } \\
\text { ter um bom aproveitamento do curso." }\end{array}$ \\
\hline $\mathrm{P} 2$ & $\begin{array}{c}\text { "Por que conhecimento se constrói melhor quando em grupo justamente por haver } \\
\text { leituras, vídeos e então trocas de experiências." }\end{array}$ \\
\hline P3 & $\begin{array}{c}\text { "Percebi que até o momento não houve grande participação dos colegas no curso, o } \\
\text { que dificulta o espaço de discussão e troca de ideias. Desta forma a leitura dos } \\
\text { materiais é que tem subsidiado o estudo." }\end{array}$ \\
\hline P4 & $\begin{array}{c}\text { "Os vídeos são mais fáceis para compreender, além de poder acessá-los em quaisquer } \\
\text { dispositivos. Por exemplo, hoje fiz esteira assistindo um dos vídeos o que foi uma } \\
\text { experiência muito interessante." }\end{array}$ \\
\hline P5 & $\begin{array}{l}\text { "Leitura nos traz reflexão teórica, a troca com os colegas nos possibilita acompanhar } \\
\text { a realidade e os vídeos permitem mais dinamismo para observar o assunto." }\end{array}$ \\
\hline P6 & "Pois agregam as várias formas e estratégias de construir a aprendizagem." \\
\hline P7 & $\begin{array}{c}\text { "Ter conteúdos e poder trocar ideias para ter um diferente ponto de vista é importante } \\
\text { para continuar um trabalho melhor e diferenciado." }\end{array}$ \\
\hline
\end{tabular}

Fonte: Elaboração própria com base na Avaliação Processual, 2016.

Em detrimento da articulação do currículo do Atendimento Educacional Especializado, a categoria mais lembrada trata da adaptação/flexibilização e o desenvolvimento da autonomia do aluno com necessidades educacionais especiais. Todavia, P3 concebe o currículo do AEE como "complementação e transversalidade dos conteúdos aplicados na sala comum".

Ampliar a autonomia do estudante no AEE implica criar as condições para que ele se aproprie dos instrumentos linguísticos e tecnológicos que lhe permitam acessar o conhecimento escolar e lhe conferir sentido e significado. Se esses instrumentos não são explorados nem dominados na sala comum, há que proporcionar esse trabalho, o domínio das tecnologias, das linguagens e símbolos, a apropriação do conhecimento, a atribuição de sentido mediante a posse das capacidades de que necessita.

RIAEE - Revista Ibero-Americana de Estudos em Educação, Araraquara, v. 13, n. 2, p. 855-871, abr./jun., 2018. E-ISSN: $1982-5587$. 
A responsabilidade do professor não é a de comparar a aprendizagem e o conhecimento dominados pelos sujeitos do AEE com aqueles da sala comum. A transversalidade que orienta o AEE relaciona-se com o suporte em termos das linguagens, práticas, instrumentos e as mediações que possam ampliar o poder de compreensão de cada sujeito. Com a posse de tecnologias, imagens, problematizações e manifestações, os estudantes do AEE poderão acessar e dominar o conhecimento que lhes seja proposto pelo professor na sala comum.

É válido mencionar o discurso de P4, que ressalta a importância da professora de AEE estar articulada com a professora da sala comum. Eis um impasse constante: na atual conjectura da educação inclusiva na modalidade de AEE, a principal fronteira consiste no diálogo entre os pares docentes.

A dificuldade na promoção da inclusão do estudante com deficiência no ensino regular, embora seja uma problemática largamente pesquisada teórica e empiricamente, Carvalho (2005, p. 15) lembra que "embora as escolas possam desenvolver inúmeras ações em prol da inclusão, também é verdade que elas enfrentam inúmeros limites que só poderão ser superados com mudanças sistemáticas nas políticas nacionais, com ênfase para as que dizem respeito diretamente à educação". Corroborando isto cabe destacar o discurso de P3, conforme o Quadro 4, quando afirma que não basta aguardar a benevolência do Estado, ao invés, é preciso buscar formação e motivar os demais pares a fazerem o mesmo.

Quadro 4: Dificuldade na promoção da inclusão do estudante com deficiência no ensino regular

\begin{tabular}{|l|c|}
\hline P1 & $\begin{array}{r}\text { "Houve uma vez que ministrei aula na Faculdade X (nome suprimido pelos autores) e } \\
\text { havia uma aluna surda. A dificuldade é não estar preparada para atuar com uma aluna } \\
\text { e com uma tradutora em sala. A tradutora "apareceu" com a aluna, sem aviso nem } \\
\text { preparo prévio. Acredito que a falta de preparação para atuar é a principal dificuldade } \\
\text { que todos os professores enfrentam." }\end{array}$ \\
\hline P2 & $\begin{array}{r}\text { "A partir da flexibilização curricular, no processo (tempo) de elaboração das } \\
\text { atividades." }\end{array}$ \\
\hline P3 & $\begin{array}{r}\text { "Acredito que o maior desafio ainda é sensibilizar alguns profissionais sobre a } \\
\text { importância de buscarem formação e não aguardar somente que o Estado o faça." }\end{array}$ \\
\hline P4 & $\begin{array}{r}\text { "Todas as possíveis, mas certamente buscando superá-las todas." } \\
\text { peculiaridades e conseguir dedicar um tempo especial para as dificuldades } \\
\text { especificas do aluno de inclusão." }\end{array}$ \\
\hline
\end{tabular}

Fonte: Elaboração própria com base na Avaliação Processual, 2016. 
A atuação do professor nas SRMF confere-lhe responsabilidade de realizar pesquisa, avaliação e formação continuadas. Organizar uma nova prática pedagógica supõe o estudo dos fundamentos teórico-metodológicos, o planejamento das etapas, o registro das observações realizadas, a análises das aquisições, dos discursos, dos instrumentos e recursos apropriados, os aspectos quantitativos e qualitativos, a categorização das produções individuais, o estudo da trajetória e os avanços individuais, a sistematização, bem como a posterior validação dos resultados. $O$ trabalho no AEE exige rigor metodológico, consistência teórica e disciplina na organização e no acompanhamento de cada sujeito.

Neste sentido, essa condição investe o trabalho do professor de cientificidade, o que lhe atribui autonomia, liberdade e autoridade para socializar e dialogar com seus pares, em termos de igualdade profissional, respeitadas as especificidade da área, da disciplina e o objeto de atuação.

Sobre a vivência do curso online em detrimento das pretensões de mudança das práticas pedagógicas pelos próprios participantes que responderam a "Avaliação Formativa", houve unanimidade nas respostas no sentido de agregação de novos saberes, oportunidade de atualização profissional, de compartilhamento de ideias entre professor tutor - cursistas e até de encorajamento, conforme observado no discurso de P4 disposto no Quadro 5.

Quadro 5: Opinião dos participantes sobre o Curso de AEE em SRMF

\begin{tabular}{|c|c|}
\hline P1 & $\begin{array}{r}\text { "Pontos positivos: diálogo entre estudantes e professores, troca de conhecimento, } \\
\text { diversos olhares; Negativos: falta de tempo maior para me dedicar; Por fim, poderia } \\
\text { ser criado um blog ou grupo no Facebook para troca de experiências." }\end{array}$ \\
\hline P2 & $\begin{array}{c}\text { "Certamente, acredito que o curso apontou possibilidades para a melhoria da } \\
\text { ação pedagógica frente ao trabalho não somente com crianças de inclusão, mas } \\
\text { como um todo. Os materiais dispostos no curso são muito interessantes e ricos em } \\
\text { conteúdo." }\end{array}$ \\
\hline P3 & $\begin{array}{c}\text { "Sim, acredito que o curso só acrescentou para minha prática. Um dos pontos } \\
\text { positivo foi em relação ao material proposto que foram bem atualizados, bem } \\
\text { selecionados. Quanto ao ponto negativo, não foi detectado, pois foi um curso } \\
\text { bastante tranquilo." }\end{array}$ \\
\hline P4 & $\begin{array}{c}\text { "Sim. Oportunizar é ação norteadora da inclusão, e é isso que devemos aos } \\
\text { estudantes em processo de inclusão. E se me permitem, gostaria de exprimir } \\
\text { apenas pontos positivos, já que pelo menos para mim, este curso de extensão veio } \\
\text { agregar novos saberes, repensar a práxis e salientar ainda mais a vontade de atuar } \\
\text { na área." }\end{array}$ \\
\hline P5 & P5 absteve-se de resposta \\
\hline
\end{tabular}

Fonte: Elaboração própria com base na Avaliação Formativa, 2016. 
Entretanto, persiste a necessidade da troca de experiências, conforme P1 afirmou em sua fala: sendo importante no ensino comum o consuetudinário da troca de experiências pedagógicas, na educação especial em Salas de Recursos Multifuncionais o compartilhamento torna-se a tônica laboral.

\section{À guisa de conclusão}

Face ao estudo realizado, concebe-se a formação continuada como necessidade no atual paradigma educacional, entretanto, é sabido que ainda não se tem um delineamento contundente acerca do que se entende por "formação", gerando um desencontro das propostas de curso de formação continuada.

Os discursos dos participantes do Curso revelaram pouco saber acerca do Atendimento Educacional Especializado realizado em Salas de Recursos Multifuncionais no que se refere às metodologias, ao currículo especializado, mas principalmente às adaptações a serem realizadas a fim de promover a inclusão do aluno com necessidades educacionais especiais. De tal modo, as expectativas apontaram para o descompasso entre aquilo que é ensinado na SRMF e na sala comum, reforçando a necessidade do diálogo e do trabalho colaborativo entre as professoras.

Se considerarmos que a essência do trabalho do AEE relaciona-se com a aquisição dos recursos de acessibilidade, linguísticos e comunicativos, poderemos construir com maior consistência a identidade do professor. Neste sentido, a formação teórica irá fundamentar-se nos processos de mediação, na posse de instrumentos tecnológicos, linguísticos e comunicativos que possibilitem ao aluno perceber a si mesmo, sua capacidade, seu lugar na família e nas relações sociais, bem como ampliar a geração de ideias, significados e sentidos, cada vez mais complexos e abstratos. Esses recursos de produção de discursos, de sentidos, de afetos e de interações entre sujeitos irão favorecer a autonomia e a posse do conhecimento escolar, trabalhado em sala comum.

Quando afirmarmos o direito à singularidade de cada estudante, a língua, principal instrumento de humanização, será ensinada para a produção de narrativas das próprias percepções e servirá menos para a classificação e separação dos sujeitos de suas capacidades criadoras. 


\section{REFERÊNCIAS}

ABED, Associação Brasileira de Educação a Distância. Censo EaD.br: relatório analítico da aprendizagem a distância no Brasil 2013. Curitiba: Ibpex, 2014.

BAPTISTA, C. R. Ação pedagógica e educação especial: a sala de recursos como prioridade na oferta de serviços especializados. Revista Brasileira de Educação Especial. Marília, v. 17, n. 1, edição especial, maio/ago., 2011.

BRASIL, Ministério da Educação. Secretaria de Educação Especial. Política Nacional de Educação Especial na Perspectiva da Educação Inclusiva. Brasília: MEC/SEESP, 2008.

BRASIL. MEC. SEESP. Nota Técnica - SEESP/GAB/N $\mathbf{0} 11 / 2010$. Sobre Orientações para a Institucionalização na Escola, da Oferta do Atendimento Educacional Especializado - AEE em Salas de Recursos Multifuncionais. Brasília, 2010.

CARVALHO, R. E. Educação Inclusiva: do que estamos falando?. Revista Educação Especial. Santa Maria, nº 26, edição 2005.

FERREIRA, W. B. Inclusão x Exclusão no Brasil: reflexões sobre a formação docente dez anos após Salamanca. In: RODRIGUES, David (org.). Inclusão e educação: doze olhares sobre a educação inclusiva. São Paulo: Summus, 2006. P. 211-238

FLICK, U. Uma introdução à pesquisa qualitativa. 2a ed. Porto Alegre: Bookman, 2004.

GIL, A. C. Métodos e Técnicas de Pesquisa Social. 6a ed. São Paulo: Editora Atlas, 2008.

JESUS, D. M. Formação de Professores para inclusão escolar: instituindo um lugar de conhecimento. In: MENDES, E. G.; ALMEIDA, M. A.; HAYASHI, M. C. P. I. (Org.). Temas em Educação Especial: conhecimentos para fundamentar a prática. Brasília: CAPES - PROESP, 2008.

MALHEIROS, B. T. Metodologia da Pesquisa em Educação. $2^{a}$ ed. Rio de Janeiro: LTC, 2011.

PALLOFF, R.; PRATT, K. O aluno virtual: um guia para trabalhar com estudantes online. Tradução de Vinícius Figueira. Porto Alegre: Artmed, 2004.

SKLIAR, C. A inclusão que é "nossa" e a diferença que é do "outro". In: RODRIGUES, D. (org.). Inclusão e educação: doze olhares sobre a educação inclusiva. São Paulo: Summus, 2006. 


\section{Como referenciar este artigo}

SILVA, Paulo Vinicius Tosin da.; BUDEL, Gislaine Coimbra.; ROSS, Paulo Ricardo. A formação continuada em atendimento educacional especializado: uma experiência no ambiente virtual de aprendizagem eureka. Revista Ibero-Americana de Estudos em Educação, Araraquara, v. 13, n. 2, p. 855-871, abr./jun., 2018. E-ISSN: 1982-5587. DOI: 10.21723/riaee.v13.n2.2018.9288

Submetido em: 08/03/2017

Aprovado em: 01/07/2017 